Pacific Journal of Mathematics

RINGS IN WHICH SEMI-PRIMARY IDEALS ARE PRIMARY 


\section{RINGS IN WHICH SEMI-PRIMARY IDEALS ARE PRIMARY}

\section{ROBERT W. GILMER}

Every ring considered in this paper will be assumed to be commutative and to have a unit element. An ideal $A$ of a ring $R$ will be called semi-primary if its radical $\sqrt{A}$ is prime. That a semi-primary ideal need not be primary is shown by an example in [3; p. 154]. This paper is a study of rings $R$ satisfying the following condition: $\left(^{*}\right)$ Every semi-primary ideal of $R$ is primary. The ring $Z$ of integers clearly satisfies (*). More generally, if $A$ is a semi-primary ideal of a ring $R$ such that $\sqrt{A}$ is a maximal ideal of $R$, then $A$ is primary. [3; p. 153]. Hence, every ring having only maximal nonzero prime ideals satisfies $\left(^{*}\right)$.

An ideal $A$ of a ring $R$ is called $P$-primary if $A$ is primary and $P=\sqrt{A}$. If ring $R$ satisfies (*), then $A$ is $\sqrt{A}$-primary if and only if $\sqrt{A}$ is prime. Some well-known properties of a ring $R$ satisfying (*) are listed below.

Property 1. If $R$ satisfies $\left({ }^{*}\right)$ and $A$ is an ideal of $R$, then $R / A$ satisfies $(*) . \quad[3 ;$ p. 148].

Property 2. If $R$ satisfies (*), if $A$ and $B$ are ideals of $R$ such that $A \subseteq B \subseteq \sqrt{A}$, and if $A$ is $\sqrt{A}$-primary then $B$ is $\sqrt{A}$-primary. [3; p. 147].

THEOREM 1. If ring $R$ satisfies (*) and $P, A$, and $Q$ are ideals of $R$ such that $P$ is prime, $P \subset A$, and $Q$ is $P$-primary, then $Q A=Q$.

Proof. Since $\sqrt{Q A}=P, Q A$ is $P$-primary. Thus $Q \cdot A \subseteq Q A$ and $A \nsubseteq P$ imply that $Q \subseteq Q A \subseteq Q$. Hence $Q A=Q$ as asserted.

THEOREM 2. If $P$ is a nonmaximal prime ideal in a ring $R$ satisfying $\left(^{*}\right)$ and if $Q$ is $P$-primary, then $Q=P$.

Proof. We let $P_{1}$ be a proper maximal ideal properly containing $P$. If $p_{1} \in P_{1}$ such that $p_{1} \notin P$ and if $p \in P$, then $Q \subseteq Q+\left(p p_{1}\right) \subseteq P$. By property $2, Q+\left(p p_{1}\right)$ is $P$-primary. Since $p p_{1} \in Q+\left(p p_{1}\right)$ and $p_{1} \notin P$, $p \in Q+\left(p p_{1}\right)$. Then for some $q \in Q, r \in R, p\left(1-r p_{1}\right)=q$. Now $1-r p_{1} \notin P_{1}$ since $P_{1} \subset R$ so that $1-r p_{1} \notin P$. Thus $p \in Q$ and $P \subseteq Q \subseteq P$. Hence $P=Q$ and our proof is complete.

Received December 28, 1961. 
CoRollaRY 2.1. If ring $R$ satisfies (*), if $P_{1}$ and $P_{2}$ are prime ideals of $R$ with $P_{1} \subset P_{2}$, and if $Q$ is $P_{2}$-primary, then $P_{1} \subset Q$.

Proof. Since $\sqrt{Q P_{1}}=P_{1}, Q P_{1}$ is $P_{1}$-primary. By Theorem 2, $P_{1}=$ $Q P_{1} \subseteq Q$. Now $Q$ is $P_{2}$-primary so that $P_{1} \neq Q$. Hence $P_{1} \subset Q$.

CoRollary 2.2. If ring $R$ satisfies (*) and $P$ is a nonmaximal prime ideal of $R$, then $P$ is idempotent.

Proof. The ideal $P^{2}$ has radical $P$ and is therefore $P$-primary. By Theorem 2, $P^{2}=P$.

THEOREM 3. If $R$ is a ring satisfying $\left({ }^{*}\right)$, if $d$ is not a zero divisor or unit of $R$, and if $P$ is a minimal prime ideal of $(d)$, then $P$ is maximal in $R$.

Proof. Suppose that $P$ is not maximal in $R$. Let $M$ denote the complement of $P$ in $R$. We define $A$ to be the set of all those elements $x$ of $R$ such that there exists $m \in M$ such that $x m \in(d)$. Since $P$ is prime, $A$ is an ideal and $A \subseteq P$. We wish to show that $P=A$. Thus if $p \in P$ and if $N$ is the set of all elements of $R$ of the form $p^{k} m$ where $k$ is a nonnegative integer and $m \in M$, then $N$ is a multiplicatively closed set containing $M$ and $p$ and hence properly containing $M$. Because $P$ is a minimal prime ideal of $(d), M$ is a maximal multiplicatively closed subset of $R$ not meeting $(d)$. [2; p. 106]. Therefore $N \cap(d) \neq \phi$ so that there exists an integer $k>0$ and an element $m$ of $M$ such that $p^{k} m \in(d)$. That is, $p^{k} \in A$ so that $p \in \sqrt{A}$. Hence $P \subseteq \sqrt{A} \subseteq \sqrt{P}=P$ which implies $P=\sqrt{A}$. This means that $A$ is $P$-primary. Under the assumption that $P$ is nonmaximal, we conclude that $P=A$ by Theorem 2. Now $P$ is also a minimal prime ideal of $\left(d^{2}\right)$ so that if $B$ is the set of elements $y$ of $R$ such that $y m \in\left(d^{2}\right)$ for some $m \in M$, we likewise have $P=B$. Since $d \in P$, there exist $m \in M$ and $r \in R$ such that $d m=$ $r d^{2}$. The element $d$ is not a zero divisor so that $m=r d \in(d) \subseteq P$ which is a contradiction to our choice of $m$. Therefore $P$ is maximal as the theorem asserts.

CoRollaRY 3.1. If ring $R$ satisfies $\left(^{*}\right)$ and if $P$ is a proper prime ideal of $R$ containing a nonzero divisor $d$, then $P$ is maximal in $R$.

Proof. There is a minimal prime ideal $P_{1}$ of $(d)$ contained in $P$. [1; p. 9]. By Theorem $3, P_{1}$ is maximal. Hence $P$ is also maximal.

CoRollary 3.2. If $J$ is an integral domain satisfying $(*)$, then nonzero proper prime ideals of $J$ are maximal. 
CoROLlary 3.3. If ring $R$ satisfies $\left({ }^{*}\right)$ and if $P$ is a proper prime ideal of $R$, then $P$ is either maximal or minimal.

Proof. Suppose that $P$ is not minimal and let $P_{1}$ be a prime ideal properly contained in $P$. Now $R / P_{1}$ is an integral domain satisfying (*) by property 1 . By Corollary 3.2, $P / P_{1}$ is maximal in $R / P_{1}$. Thus $P$ is maximal in $R$. [3; p. 151].

THEOREM 4. If ring $R$ satisfies (*) and $P$ is a finitely generated nonmaximal prime ideal of $R$ then $P$ is a direct summand of $R$. If $P_{1}$ is a prime ideal not containing $P$, then $P$ and $P_{1}$ are relatively prime.

Proof. By Corollary 2.2, $P=P^{2}$. Since $P$ is finitely generated, there exists an element $e \in P$ such that $(1-e) P=(0)$. [3; p. 215]. Evidently $e^{2}=e, P=(e)$ and $R=P \oplus(1-e)$. Now $e(1-e) \in P_{1}$ and $e \notin P_{1}$ so that $1-e \in P_{1}$. Therefore $1=e+(1-e) \in P+P_{1}$ so that $P$ and $P_{1}$ are relatively prime.

THEOREM 5. If the Noetherian ring $S$ satisfies (*), $S$ is a finite direct sum of Noetherian primary rings and Noetherian integral domains in which nonzero proper prime ideals are maximal. Conversely if $T$ is a finite direct sum of Noetherian primary rings and Noetherian integral domains in which nonzero proper prime ideals are maximal, then $T$ is a Noetherian ring satisfying $\left({ }^{*}\right)$.

Proof. Since $S$ is Noetherian, every ideal of $S$ is finitely generated. Let $(0)=Q_{1} \cap \cdots \cap Q_{s}$ be an irredundant representation of $(0)$ as an intersection of greatest primary components where $P_{i}=\sqrt{Q_{i}}$. If $P_{1}$, $P_{2}, \cdots, P_{k}$ are the nonmaximal prime ideals of $S$ in this collection, $P_{i}=$ $Q_{i}$ for $1 \leqq i \leqq k$ by Theorem 2 . If $1 \leqq i<j \leqq s, P_{i}+P_{j}=S$. This follows from Theorem 4 if $P_{i}$ and $P_{j}$ are nonmaximal. If $P_{j}$, say, is maximal, then $P_{j} \nsupseteq P_{i}$ by Corollary 2.1 , for $Q_{j} \nsupseteq P_{i}$ from the irredundance of the representation. Therefore, $P_{i}+P_{j}=S$. Thus the $P_{i}$ 's, and hence the $Q_{i}$ 's, are pairwise relatively prime. [3; p. 177]. This means that $S \cong S / P_{1} \oplus \cdots \oplus S / P_{k} \oplus S / Q_{k+1} \oplus \cdots \oplus S / Q_{s}$. [3; p. 178]. Each $S / P_{i}$ in this representation is a Noetherian integral domain in which nonzero prime ideals are maximal. Since $Q_{j}$ for $k+1 \leqq j \leqq s$ is $P_{j}$ primary with $P_{j}$ maximal, $S / Q_{j}$ is a Noetherian primary ring. [3; p. 204].

The converse follows from elementary facts concerning the ideal theory in a finite direct sum since it is apparent that each summand satisfies $(*)$.

We give the following example of ring which is not a finite direct 
sum of indecomposable summands and which satisfies (*).

Let $S=\sum_{i=1}^{\infty w} Z_{i}$, where each $Z_{i}$ is the ring of integers and $\sum_{i=1}^{\infty w}$ designates the weak direct sum. Let $R=S+Z$ be the usual extension of $S$ to a ring with unit element. [2; p. 87]. Clearly $S$ is a prime ideal of $R$, as is $I_{p}=S+p Z$ for every prime $p$ of $Z$. In fact, each $I_{p}$ is a maximal ideal of $R$. It is easy to show that there is no prime ideal $P$ between $S$ and $I_{p}$.

Next, assume that $P$ is a prime ideal of $R$ that does not contain all of $S$. Then some $e_{k} \notin P$, where $e_{k}$ is the unity of $Z_{k}$. However, since $e_{j} e_{k}=0$ for every $j \neq k$, evidently $Z_{k} \subset P$ for every $j \neq k$. By the same reasoning, $\left(1-e_{k}\right) R \subseteq P$. As before, it is easily shown that either $P=\left(1-e_{k}\right) R$ or $P=\left(1-e_{k}\right) R+p e_{k} R$ for some prime $p$.

Knowing precisely what the prime ideals of $R$ are, it is just a routine matter to check that $R$ satisfies $\left(^{*}\right)$.

The author is not able to give necessary and sufficient conditions which he feels are adequate that an arbitrary ring satisfy $\left(^{*}\right)$. The condition of Corollary 3.3, while necessary, is not sufficient to imply that a ring satisfy $(*)$ as is shown by the following example.

If $S$ is the ring of polynomials in two indeterminates $X$ and $Y$ over a field $K$, then every nonzero proper prime ideal of $S$ has height 1 or 2. [4; p. 193]. Therefore if $A=(X Y)$ and if $R=S / A, R$ is a Noetherian ring in which every prime ideal is maximal as minimal. The nonmaximal prime ideal $(X) / A$ of $R$, however, is not idempotent so that $R$ does not satisfy $(*)$.

\section{BIBLIOGAPHY}

1. W. Krull, Idealtheorie, (New York, 1948).

2. Neal H. McCoy, Rings and Ideals, (Menasha, Wisconsin, 1948).

3. O. Zariski, and Pierre Samuel, Commutative Algebra. V.I. (Princeton, 1958).

4. O. Zariski, and Pierre Samuel, Commutative Algebra. V. II. (Princeton, 1960). 


\section{PACIFIC JOURNAL OF MATHEMATICS}

\section{EDITORS}

\author{
Ralph S. Phillips \\ Stanford University \\ Stanford, California \\ M. G. Arsove \\ University of Washington \\ Seattle 5 , Washington
}

\author{
A. L. Whiteman \\ University of Southern California \\ Los Angeles 7, California \\ Lowell J. Paige \\ University of California \\ Los Angeles 24, California
}
E. F. BECKENBACH
D. DERRY
ASSOCIATE EDITORS
T. M. CHERRY
M. OHTSUKA
H. L. ROYDEN
E. G. STRAUS
E. SPANIER
F. WOLF

\section{SUPPORTING INSTITUTIONS}

\author{
UNIVERSITY OF BRITISH COLUMBIA \\ CALIFORNIA INSTITUTE OF TECHNOLOGY \\ UNIVERSITY OF CALIFORNIA \\ MONTANA STATE UNIVERSITY \\ UNIVERSITY OF NEVADA \\ NEW MEXICO STATE UNIVERSITY \\ OREGON STATE UNIVERSITY \\ UNIVERSITY OF OREGON \\ OSAKA UNIVERSITY \\ UNIVERSITY OF SOUTHERN CALIFORNIA
}

\author{
STANFORD UNIVERSITY \\ UNIVERSITY OF TOKYO \\ UNIVERSITY OF UTAH \\ WASHINGTON STATE UNIVERSITY \\ UNIVERSITY OF WASHINGTON \\ AMERICAN MATHEMATICAL SOCIETY \\ CALIFORNIA RESEARCH CORPORATION \\ SPACE TECHNOLOGY LABORATORIES \\ NAVAL ORDNANCE TEST STATION
}

Mathematical papers intended for publication in the Pacific Journal of Mathematıcs should be typewritten (double spaced), and the author should keep a complete copy. Manuscripts may be sent to any one of the four editors. All other communications to the editors should be addressed to the managing editor, L. J. Paige at the University of California, Los Angeles 24, California.

50 reprints per author of each article are furnished free of charge; additional copies may be obtained at cost in multiples of 50 .

The Pacific Journal of Mathematics is published quarterly, in March, June, September, and December. Effective with Volume 13 the price per volume (4 numbers) is $\$ 18.00$; single issues, $\$ 5.00$. Special price for current issues to individual faculty members of supporting institutions and to individual members of the American Mathematical Society: $\$ 8.00$ per volume; single issues $\$ 2.50$. Back numbers are available.

Subscriptions, orders for back numbers, and changes of address should be sent to Pacific Journal of Mathematics, 103 Highland Boulevard, Berkeley 8, California.

Printed at Kokusai Bunken Insatsusha (International Academic Printing Co., Ltd.), No. 6, 2-chome, Fujimi-cho, Chiyoda-ku, Tokyo, Japan.

PUBLISHED BY PACIFIC JOURNAL OF MATHEMATICS, A NON-PROFIT CORPORATION

The Supporting Institutions listed above contribute to the cost of publication of this Journal, but they are not owners or publishers and have no responsibility for its content or policies. 


\section{Pacific Journal of Mathematics}

\section{Vol. 12 , No. 4 \\ April, 1962}

Tsuyoshi Andô, On fundamental properties of a Banach space with a cone ..... . 1163

Sterling K. Berberian, A note on hyponormal operators ................ 1171

Errett Albert Bishop, Analytic functions with values in a Frechet space . . . . . . . 1177

(Sherman) Elwood Bohn, Equicontinuity of solutions of a quasi-linear equation ............................................ 1193

Andrew Michael Bruckner and E. Ostrow, Some function classes related to the class of convex functions . . . . . . . . . . . . . . . . . . . . . . . . 1203

J. H. Curtiss, Limits and bounds for divided differences on a Jordan curve in the complex domain . . ................................. 1217

P. H. Doyle, III and John Gilbert Hocking, Dimensional invertibility . . . . . . . . 1235

David G. Feingold and Richard Steven Varga, Block diagonally dominant matrices and generalizations of the Gerschgorin circle theorem ................. 1241

Leonard Dubois Fountain and Lloyd Kenneth Jackson, A generalized solution of the boundary value problem for $y^{\prime \prime}=f\left(x, y, y^{\prime}\right) \ldots \ldots \ldots \ldots \ldots \ldots \ldots \ldots \ldots$

Robert William Gilmer, Jr., Rings in which semi-primary ideals are primary. . . . . 1273

Ruth Goodman, K-polar polynomials .......................... 1277

Israel Halperin and Maria Wonenburger, On the additivity of lattice completeness ........................................... 1289

Robert Winship Heath, Arc-wise connectedness in semi-metric spaces . . . . . . . . 1301

Isidore Heller and Alan Jerome Hoffman, On unimodular matrices . . . . . . . . . . . 1321

Robert G. Heyneman, Duality in general ergodic theory . . . . . . . . . . . . . . . 1329

Charles Ray Hobby, Abelian subgroups of p-groups . . . . . . . . . . . . . . . 1343

Kenneth Myron Hoffman and Hugo Rossi, The minimum boundary for an analytic

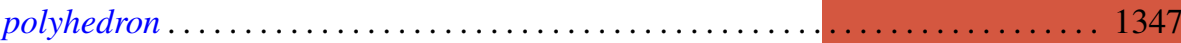

Adam Koranyi, The Bergman kernel function for tubes over convex cones ........ 1355

Pesi Rustom Masani and Jack Max Robertson, The time-domain analysis of a continuous parameter weakly stationary stochastic proces.

William Schumacher Massey, Non-existence of almost-complex structures on

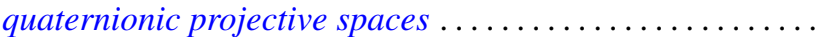

Deane Montgomery and Chung-Tao Yang, A theorem on the action of $\mathrm{SO}(3) \ldots . .1385$

Ronald John Nunke, A note on Abelian group extensions . . . . . . . . . . . . . 1401

Carl Mark Pearcy, A complete set of unitary invariants for operators generating finite $W^{*}$-algebras of type $I$

Edward C. Posner, Integral closure of rings of solutions of linear differential equations.

Duane Sather, Asymptotics. III. Stationary phase for two parameters with an application to Bessel functions.

J. Śladkowska, Bounds of analytic functions of two complex variables in domains

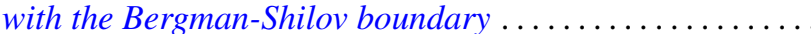

Joseph Gail Stampfli, Hyponormal operators .

George Gustave Weill, Some extremal properties of linear combinations of kernels

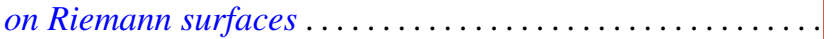

